[Vicino Oriente XVI (2012), pp. 181-199]

\title{
FROM FLINT TO SILICON, MODERN TECHNOLOGIES APPLIED TO THE UNDERSTANDING OF HISTORY. THE ITALIAN ARCHAEOLOGICAL MISSION IN IRAQI KURDISTAN
}

\author{
Carlo G. Cereti - Luca Colliva - Maria Vittoria Fontana - Gianfilippo Terribili - \\ Sapienza University of Rome - \\ Julian Bogdani - BraDypUS, Bologna - \\ Angela Bizzarro - Alessandro Tilia - Stefano S. Tilia - Studio 3R s.a.s., Rome
}

Dal 2011 La MAIKI opera nei governatorati di Erbil e Sulaimaniya, e focalizza le sue attività sulla Cittadella di Erbil e sul sito di Paikuli.

Gli studi storico-archeologici sui siti sono stati affiancati da importanti attività di documentazione e gestione dei dati caratterizzate dall'utilizzo di alcune tra le più moderne risorse a disposizione.

Keywords: archaeological prospections; Erbil Citadel; GIS; Paikuli monument; photogrammetry

\section{THE ITALIAN ARCHAEOLOGICAL MISSION IN IRAQI KURDISTAN}

The Italian Archaeological Mission in Iraqi Kurdistan (MAIKI, Missione Archeologica Italiana nel Kurdistan Iracheno), run jointly by the Department of Ancient World Studies (DiSA) of Sapienza - University of Rome and by the Istituto Italiano per l'Africa e l'Oriente (IsIAO), aims at addressing a number of issues related to the history of the Kurdish region of Iraq by combining modern technologies and more traditional methodologies to study the Kurdish territory and its relevant cultural heritage. The Kurdish region of Iraq is a border area from a geographical point of view, marking as it does the passage between the Zagros Mountains and the Mesopotamian plain, and it has also been, at least in some historical periods, a borderland from the perspective of political history. Today the area is inhabited mostly by Kurds and it is rather homogenous as regards to language, since most of its dwellers speak varieties of Kurdish. Nonetheless, due to its being a frontier region traditionally of difficult access, still today it hosts many religious and sometimes also linguistic minorities - such as Christians of different belonging, Ahl-e Haqq, Yazidis, Kākā’i, etc.

Given the complex context and the existence of marked differences between the plains and the hills, MAIKI has chosen to focus its activities on two areas of the region, one in the Sulaimaniya province, the other in the city of Erbil. In the Sulaimaniya province the Italian archaeological mission has undertaken a vast research plan aimed at tracing a detailed map of Sasanian presence in the area. To this effect we are now studying the Paikuli monument while preparing a volume planned to appear by the end of 2013 , which will contain the inscription as well as a very detailed documentation of the monument. To complement this research MAIKI is preparing a detailed archaeological map of the districts of Darband-i Khan and Chamchamal which will hopefully provide a model for the rest of the region. The activities in the province of Sulaimaniya are run under close cooperation with the local Directorate of Cultural Heritage and the Museum of Sulaimaniya, both under the aegis of the Ministry of Tourism and Heritage (MoTH). The second focus of activity is the historical Citadel of Erbil, an imposing and endangered site characterized by an extremely 
long history of human inhabitation that the government of the Repubblic of Iraq and the Kurdish Regional Government are proposing to be included in the list of Unesco World Heritage Sites. Here our activities are for the time being limited to non-invasive surveys, mainly by georadar, documentation as well as cartographical and topographical studies. The High Commission for the Erbil Citadel Revitalization (HCECR), our main partner in the province, is presently planning to begin archaeological activities in the Citadel and therefore we hope to be able to choose an area to excavate in the near future. Both approaches, however, converge on the need of a better understanding of the relationship between the Iranian plateau and the Mesopotamian plains in historical times, which may also be understood within the dialectic centre-periphery that has been an important focus of recent scientific debate.

Though MAIKI is only active since 2011, it can profit from a comparably long experience on field, since it inherits the staff and competence of the many cooperation missions in the field of cultural heritage present in the Kurdish region of Iraq since 2006, which were organized first by IsIAO and presently by Sapienza through DiSA.

Carlo Giovanni Cereti - Maria Vittoria Fontana

\section{TOPOGRAPHICAL AND CARTOGRAPHICAL APPLICATIONS}

During the excavation and documentation activities regarding the Paikuli monument, carried out since the end of September 2006 in the region of Iraqi Kurdistan, a systematic topography campaign was commenced. Such activity, finalized towards a correct relative placement of both the excavation and the visible archaeological artifacts, was undertaken, through the use of a total station, by establishing a closed polygonal traverse from which the excavation grid, the survey of the architectural remains of the structure, longitudinal and transversal sections and the positioning of all scattered blocks belonging to the monument itself, were realized. What remained to be done was the positioning of the site within a more general and possibly global reference system. Following a careful research of available cartographies, capable of encompassing the three provinces of Iraqi Kurdistan (Dahuk, Erbil and Sulaymaniyah), a set of Russian military maps in scale 1:100,000 were chosen. These maps presented a series of issues such as difficulties in readability due to the transliteration of toponyms into the Cyrillic alphabet and various types of imprecisions. In order to produce an acceptable cartography in a larger scale it was decided to resort to aerial photogrammetry. Since aerial photography was not readily available, satellite photography was deemed as the solution. The choice fell upon the Quickbird (DigitalGlobe $^{\circledR}$ ) sensor due to its up to $61 \mathrm{~cm}$ (per pixel) ground resolution, the presence of both the panchromatic and multispectral bands and the possibility of acquiring archival images immediately (as opposed to waiting for the appropriate satellite time window in which to capture the requested image). As a first step, among the 5 strips available in the archive, the 2 which could provide the best stereoscopic base were chosen; successively two images were extrapolated from these two strips with a $100 \%$ overlap comprising an area of $75 \mathrm{~km}^{2}(15 \times 5 \mathrm{~km})$. The two chosen images, obtained through the union of the panchromatic and the three visible bands (RGB), were of the orthoready kind. They also 
possessed the necessary polynomial coefficients (RPC) for the achievement of the proper relation between object space and image space. ${ }^{1}$ By analyzing the images with the INPHO $\left(\right.$ Trimble $\left.^{\circledR}\right)$ digital photogrammetry software it was clear that the RPCs by themselves wouldn't have enabled a satisfactory orientation of the images since parallax issues persisted between them. In the light of this fact it was necessary to acquire a number of ground control points (GCP) directly on the territory depicted in the images. For this purpose, a careful analysis of the images enabled us to locate a number of possible points that could be useful for our goal. In any case, the search proved quite problematic due to the rugged nature of the terrain we were dealing with and to the differences between the two images, which had been extrapolated from strips acquired in two very different epochs, November 2002 and July 2006 respectively, making it very hard to find recognizable common on both images. The survey of the GCPs was carried out through the use of differential GPS system (DGPS) based on the use of two double frequency GPS antennas, of which the first (reference) positioned on a point of known coordinates while the second (rover) used for the actual point survey. The first objective was that of establishing the base (reference) station next to the site of Paikuli and providing it with absolute world coordinates (WGS84 datum). Due to the apparent unavailability (at the time of survey) of any nearby datum point, it was decided to resort to the IGRS (Iraqi Geospatial Reference System) permanent stations which had been set up within the project for the reconstruction of Iraq's national geodetic network. ${ }^{2}$ Such stations are part of the CORS (Continuously Operating Reference Stations) belonging to the NGS (National Geodetic Survey) and are able to provide the necessary data capable of correcting GPS field measurements. The base station (reference) was acquired through a long static measurement and corrected by using the contemporary CORS data, while the $11 \mathrm{GCPs}$, which were positioned at roughly the four corners and at the center of the reference area, were also acquired through static albeit brief measurements. The chosen points, rigorously on the ground, constituted mostly of easily recognizable (both in the images and on the ground) rock formations, low walls belonging to cemeterial structures or herd retaining fences and building corners of very low height due to their setting on inclined terrain. The points were then calculated in post processing and used for the refinement of the stereo couple's orientation. Radiometric corrections were also applied in order to obtain a more homogenous rendering of the two images. The next step was the DTM (Digital Terrain Model) extraction through an automatic process which gave as a result a regular grid of elevation points with a $15 \mathrm{~m}$ spacing (fig. 1). The last step was the generation of the orthophotos through the use of the stereo couple and the generated DTM, the latter which also produced a $10 \mathrm{~m}$ interval contour level map by its processing through appropriately equipped CAD software (fig. 1).

On the base of this experience the problem of creating an accurate elevation map of the Citadel of Erbil was approached. This also thanks to the availability of a new generation of satellite sensors capable of providing built-in stereophotogrammetry ready images. The choice fell upon the Worldview-2 (DigitalGlobe ${ }^{\circledR}$ ) satellite. This sensor is capable of acquiring panchromatic and multispectral images with a resolution of $50 \mathrm{~cm}$ per pixel (on

Dial - Grodecki 2002, vol. 34, part. XXX.

2 Yenter et al. 2005, 12-22. 
the ground). Even if this sensor also provides polynomial coefficients for orientation, parallax issues were again present for the given stereo couple and this fact forced us to search and measure GCPs once again. In this case, the GPS measurements were facilitated by the presence of a CORS station within the same urban premises. On the other hand, some difficulties were given by the vastness of the area $\left(315 \mathrm{~km}^{2}\right)$ covered by the images and by the fact that many of the points needed to be obligatorily placed in the more rural areas of the city, where recognizable features are notoriously scarce. The same criteria for the choice of points was applied as in the case of the Quickbird images, that is by searching for a minimum of 5 points (one in the center and four placed roughly at the 4 corners of the images). After the orientation refinement which effectively eliminated the parallax problems, the calculation in this case of the DSM (Digital Surface Model) instead of the DTM, was commenced. The DSM is more apt in capturing the density of features which are usually present in an urban setting. The obtained DSM produced a grid of elevation points with a spacing of $4 \mathrm{~m}$ (fig. 2). In order to use such grid in the generation of a true orthophoto, a number of vector elements must be necessarily introduced and these will derive from for example the 3D digitalization of the building limits and all other elevated features that may be found within a city environment.

The use of satellite photography, especially through what can be provided by the new generation sensors, enables the realization, thanks to the modern digital photogrammetric techniques, of that fundamental cartography indispensable in archaeological research and in (in this case) urban planning. The procedures here described will be streamlined further thanks to sensors such as Geoeye ${ }^{\circledR}-1$ in which the need for GCPs will be drastically reduced thanks to the accuracy in geolocation. ${ }^{3}$

Alessandro Tilia - Stefano Sven Tilia

\section{ACQUISITION OF DATA AND CLOSE-RANGE DIGITAL PHOTOGRAMMETRY FOR THE SURVEY AND DOCUMENTATION OF ARCHITECTURAL ELEMENTS AND DECORATED SURFACES}

The programming and the time deadline of the activities concerning the survey and the graphic documentation of both architectural elements and decorated surfaces, led to the choice of methods and techniques to be used in order to be able to combine an accurate topographic and detail survey with the most modern technologies applied to surface scanning and digital photogrammetry.

Two different themes were tackled, concerning the typology of the data to be documented and their localization. The first refers to the digital processing of the $3 \mathrm{D}$ model, obtained through digital photogrammetry acquisition, of the Sasanian monument of Paikuli as an architectural structure surveyed in situ (fig. 3) and successively, the acquisition of data as plan and prospect orthophoto creation concerning 111 among molded and inscribed blocks belonging to the same monument, (such activity, directly connected with philological studies, is finalized to the digital graphic reconstruction both of the

3 Fraser - Ravanbakhsh 2009, 634-638. 
monument and the inscriptions). ${ }^{4}$ The second theme consisted in the the graphic documentation (plans, prospects and sections) of the Rashid Agha Diwan Khanah, one of the most significant houses belonging to the Citadel of Erbil. Such documentation was finalized towards a complete knowledge of the state of conservation of the building on which to base a restoration project.

In its whole, the Paikuli tower was constituted by an outer coating of rectangular stone blocks, covering a nucleus composed by a mixture of stones and mortar. Today these blocks have all fallen off from their original position and due to a very concrete risk of looting, the inscribed ones and most of the molded ones, such as battlements, semi columns and the massive busts of Narseh, have been removed and taken to the Museum of Sulaimaniya for safekeeping. ${ }^{5}$ As mentioned, some of the blocks are inscribed, those covering the two walls where Narseh engraved his inscription, some are moulded in different shapes, those composing the decorative features of the monument, whereas all the others, the majority, have one flat quadrilateral face, the face opposite to the flat one being roughly worked in pyramidal shape.

The stone used for the monument is a soft chalky limestone and the working signs, still visible on the stone, show that the stone workers used hammers and chisels for the roughshaping and tooth and point chisels and bush hammers for the finishing of the flat external face.

The two sockets for the clamps are still visible on the upper surface of most the blocks, but only very few traces of metal were discovered into these. Perhaps the locals in search of metal have contributed to the dismantling of the monument as well as natural and physical phenomenons, such as an earthquake or structural shortcomings. ${ }^{6}$

Over the centuries another natural phenomenon has affected the stones of the Paikuli ruin, for in the valley where the monument is placed very strong winds blow almost incessantly, ${ }^{7}$ carrying siliceous sand at great speed. This causes a sanding effect, whose consequences are clearly visible on the surface of the inscribed blocks that were long exposed to the wind. These faces not only are eroded, but show craters and worm-shaped canals. This kind of erosion is probably due to micro-whirls formed inside the natural cavities of the stone that multiplied the speed of wind.

On some blocks bio-degradation, mostly due to the presence of algae, lichens, fungi and cyanobacteria colonies, is clearly visible. The stone of most of the blocks is sound and

4 The authors wish to thank Barbara Faticoni, director of the archaeological excavation of 2006 and author of the archaeological report and Dario Marletto, who was in charge of conservation, for the indispensable information each of them contributed to this paper.

5 Thanks to the joint efforts of Abdulraqib Yussuf, Kamal Nuri Ma'aruf and Hashem Hama Abdullah, in the winter of 1997 the majority of inscribed blocks were moved from the site to the Museum of Sulaimaniya and placed in a storeroom for safekeeping, other few inscribed blocks were transferred to the Museum after our archaeological campaign on the Paikuli site in 2006. We hereby wish to thank Kamal Rasheed Raheem and Hashem Hama Abdullah, respectively Director of Antiquities of Sulaimaniya and Director of the Sulaimaniya Museum for their constant support to our project.

6 Cereti - Terribili 2012, 85

7 During his first trip to Paikuli Herzfeld has recorded in his diary the strength of the wind blowing on the hill (Cereti - Terribili 2012, 80). 
structurally well preserved; however, some blocks present fractures or missing parts; this may in part be due to the collapse of the monument or to its dismantling, but much of the damage is demonstrably more recent as can be easily made visible by comparing Herzfeld's photos of some of the inscribed blocks and probably due to the military events that involved this region between the ' 80 s and the ' 90 s of XX century.

The inscription text covers a total of fifteen tiers, counting both versions of it, the Middle Persian and the Parthian. The MP version is displayed on eight tiers for a total of 46 textual lines, whereas the text of the Parthian version consists of 43 lines carved on seven tiers. ${ }^{8}$ The distribution of textual lines for each tier changes, from five up to seven, probably following the original structural features of the monument.

Professional stonemasons played great care carving this royal inscription, since letters, words and the blank spaces between them are quite regular in size and shape. The so-called monumental script, common to Sasanian inscriptions of the third century, in which each sign is well separated from the others, was a fairly homogeneous writing system with a steady ductus and was also used at Paikuli. Moreover, The inscription has been written in perspective, with the upper tiers having taller and larger letters reaching their smallest dimensions on the last tier, in order to facilitate its legibility from below. To give only two examples from the MP text, the largest examples of the letter aleph measure $4.7 \mathrm{~cm}$ in height, while the smallest measure $1.5 \mathrm{~cm}$. The same is true for the lāmed, a letter rising above the regular ductus of the Middle Persian script: the largest examples are $10.4 \mathrm{~cm}$ tall, decreasing progressively to a height of $4.6 \mathrm{~cm} .{ }^{9}$

The 3D documentation campaign, lead in the spring of 2009, covered all the 105 inscribed blocks held in Sulaimaniya Museum and the best preserved examples for each typology of moulded blocks. The technical devices now available allow an integrated survey capable, depending on the case, of combining information gathered through different methods: in the present case-study the traditional mapping systems were associated with topographical survey, surface scanning and digital photogrammetry. All the surfaces were documented through the use of the Menci Software ZScan system (3D models and true orthophotographs), a system which allows the creation of 3D models of surfaces and - through their subsequent processing - the mosaics of metrically corrected and measurable ortho-rectified images. Unlike the usual photographic images, the digital documentation obtained through this methodology allows multiple output applications, such as the digital draft of the decorations or the definition of layers of the different states of preservation of the walls.

The ZScan system, an instrument for the acquisition of point clouds, comprises of a high resolution digital SLR camera equipped with a fixed (non-zooming) focal length lens, calibrated within Menci Software's laboratory. Such camera is then placed on a precision manufactured bar on which a small recirculating balls carriage, on which the camera is fixed, can slide along and stop at a number of fixed points. Such setup enables the acquisition of three images, one at the center of the bar and the two others at equal

8 Following the reconstruction made first by Herzfeld and confirmed by the new edition of Humbach and Skjærvø (Humbach - Skjærvø 1978-1983, 8).

9 Cereti - Terribili 2012, 86 
distances, both to the right and to the left of the center. The processing software, through a multi-focal analysis algorithm, is capable of obtaining a 3D model of the object acquired by the 3 images taken from the prefixed points along the precision bar. The resulting point clouds have the correct photographic grade color associated to each and every point and it is possible to visualize the images directly applied onto the $3 \mathrm{D}$ model as raster textures. The post-processing phases of the point clouds (editing, merging, orthophoto generation, exporting, etc.) are carried out through the use of the ZMap software also produced by Menci Software.

In the case of the survey of the Rashid Agha Diwan Khanah, the methodology used implied a very careful survey, with a high metric precision. For the detail-scale documentation of the actual state of conservation of the Diwan Khanah a great number of plans (the main floor - including the eastern area and the harem in the west - the underground floor and the roofs), prospects and section/prospects were realized (figs. 4-5). The great amount of digital graphic restitutions were focused on the drafting of different aspects of the restoration project: from the structural and architectonic one to that related to the wall surfaces, building techniques and analysis of the decoration elements.

The entire documentation is part of a wider georeferenced system concerning the Erbil Citadel, in fact, this complex system of data acquisition, in both the examined study cases, has been used also in order to be closely connected by the geographic reference of the data, managed through an Geographical Information System (GIS) in which the different kinds of information, from the general to the detailed plan, to the sampling areas, with all the related data, are contextualized.

Angela Bizzarro - Gianfilippo Terribili

\section{GROUND PENETRATING RADAR SURVEY ON ERBIL CITADEL}

Thanks to the agreements between HCECR, directed by Arch. Dara Talaat Mohammed Ali al-Yaqoobi, MAIKI and IsIAO-MAE Cooperation Projects a survey campaign using Ground Penetrating Radar (GPR) started in October 2010, with the specific purpose of gathering data for the stratigraphic analysis of the Erbil Citadel and achieving a deeper comprehension of its ancient development. The geophysical prospections were carried out in collaboration with UTT-MAT of ENEA. ${ }^{10}$

A working strategy which involves employment of non-invasive geo-archaeological explorations was planned in order to collect the largest amount of useful information before planning the starting of - necessarily destructive - extensive archaeological excavations inside an urban context of great importance and inhabited until the second half of the 20th century. The choice of a GPR survey is due to the status of the Citadel and to the desire to collect as much data as possible. The presence in the Citadel of many electrical cables and metal water pipes makes geomagnetic prospection useless and seismic prospections,

10 The prospections were carried out by Luca Colliva, archaeologist of "Sapienza" University of Rome, Alessandro Colucci, technician of ENEA and Giolj F. Guidi, in collaboration with the topographers Angela Bizzarro and Sven Stefano Tilia, the Chief Architect of HCECR, Ranan Khasraw Tawfiq, the Architect Bafren Abdul Qadir Ali and the Civil Engineer, Jaafer Saeed Ibrahim. 
already partially realized in 2006 by a Kurdish-Czech mission and therefore postponed to a later date, are planned for spring 2013.

\subsection{The Ground Penetrating Radar}

The GPR $^{11}$ is a non destructive method used to carry out non-invasive geophysical prospections and allows the detection of various kinds of discontinuities. Through the reflection of electromagnetic waves onto reflectors (anomalies or discontinuities), the GPR gives, as a result, a series of maps and sections of the investigated medium with the interpretative detection of the presence and approximate depth of anomalies in the medium itself. In recent years the use of GPR for geophysical surface exploration has been increasingly widespread, and there was a significant rise of interest in this methodology, both for the non-invasive character, and for the high accuracy achieved through the development of specific software applications. In particular, this technology has been recognized as particularly useful in the field of archaeology for its reliability in detecting walls, metallic objects and cavities of different size (such as burial chambers, catacombs, cisterns and wells).

\subsection{The campaign of prospections on the Citadel}

The campaign took place 5th to 25 th October 2010 and lasted 20 days, during which 42 areas were surveyed, for a total of approximately $5.000 \mathrm{~m} 2$ (fig. 6). The survey was carried out using a GPR RIS-2K/MF 200-600 MHz with four antennas.

The investigated areas were chosen in consultation with HCECR; at first the three areas indicated in the Master Plan of the Citadel as areas for possible future archaeological excavations were selected: the central square; a north-eastern area, corresponding to Block 36 and its immediate neighbourhood and a western area, corresponding to Block 50 and its immediate neighbourhood. Afterwards, on site surveys, meetings with HCECR staff and preliminary results urged us to explore some more areas of the Citadel: the main street (Citadel Street), which crosses the Citadel for its entire length along the north-south axis, a small open space (currently used as a parking area) located to the east of the southern gate and some sectors in the southern part of Citadel and along the external perimeter. The north-south axis was chosen for its position and for the possibility to compare data with those of the Kurdish-Czech mission. ${ }^{12}$ The parking area and the other areas near the external perimeter were selected as particularly suited for the identification of possible fortifications.

\subsection{Results of the investigations and some interpretive hypotheses}

The composition of the soil (prevailingly clayey) and the high level of humidity, common to all the areas under investigation, have significantly limited the penetrating power of the radar: the area clearly visible reaches the depth of about 2-3 m; between 4 and $9 \mathrm{~m}$. the signal is strongly attenuated and the results are only partially reliable; below this level the signal disappeared.

11 Conyers 2004; Daniels (ed.) 2007.

12 Novácek 2009, 209-211. 
The propagation speed, suitable to define the depth, was calculated by approximation, using the results of four cores carried out for the realization of the Conservation and Rehabilitation Master Plan: the interface between the first and the second layer identified in the cores was quite evident in the radar prospections and. this comparison made possible to calculate the propagation speed in the soil. The comparison between the calculated speed and the reference tables allowed to establish that the detected archaeological stratigraphy is largely composed of clay materials.

The high number of anomalies found (fig. 7), their presence in almost all the investigated areas and the different depths at which these anomalies appear confirm the existence of a very complex stratigraphy, unfortunately mainly unidentified. These data also decisively strengthen the hypothesis, already supported by the results of the four cores carried out in 2009, that the hill on which the Citadel stands might be a tell formed as a result of the accumulation and erosion of masonry structures and materials resulting from the human occupation of the area.

Comparing these anomalies with data collected during a small stratigraphic test opened in 2006 by the Kurdish-Czech mission, ${ }^{13}$ it is possible to conclude that the anomalies detected in the first $2.5 \mathrm{~m}$ correspond to 19th century structures, partly still visible in the 1920 cadastral map. The most interesting data, however, come from the areas along the perimeter wall where several large anomalies were found. Position and typology of these anomalies (fig. 8) seem to indicate the presence of fortifications or defensive structures near the external perimeter of the Citadel. At present it is almost impossible to date these remains, although their depth allows to suppose an Ottoman chronology. However, we cannot exclude the possibility that the original core of these structures, certainly reinforced and rebuilt several times over the centuries (given the numerous sieges that the town had to face), can date back to the Begteginid period.

Luca Colliva

\section{GIS PLATFORM AND RELATIONAL DATABASES}

From its beginning, a main priority of MAIKI has been to share and transmit to the Kurdish colleagues and authorities the results achieved in the field research. Moreover, a major aim has been to promote and encourage communication and exchange of experience and know-how on research methodologies, with particular attention to the new technologies for the documentation of archaeological data. The geographic information system (GIS) was selected as best platform for integrating these different objectives into a single coherent workflow. The GIS was planned as the main working tool for the collection, management, analysis and processing of data and field research results, as well as the main tool for sharing and transmitting research methodologies and results. ${ }^{14}$ This second aspect takes even greater importance considering that a comprehensive and real-time sharing was a compelled precondition to the activities of MAIKI, given the highly multidisciplinary

13 Novacek 2009, 212-214

14 Lock - Stančič 1995; Barceló - Pallarés 1996; Forte 2002; Bogdani 2009a; Bogdani - Giorgi 2010; Palumbo Agnew - Myers 2009. 
aspect of the project. ${ }^{15}$

From these initial considerations, a further characteristic that computer system had to provide from the beginning becomes evident: the data shall be always available to all the members of MAIKI and to its collaborators during all the phases of the project. This ruled out the choice of a traditional desktop GIS platform that, if very efficient and powerful in terms of execution, raises the problem of the physical location of data and their access by all staff members. The platform could not be placed on standalone computers in Iraq. Even if this, from one side, would facilitate the field work, on the other it would undoubtedly affect the consultation and / or analysis of the data out of the country and made difficult maintenance work. For this reasons we opted for a cloud computing solution, namely the development of a management server system for all the data, which would make possible to access and display all files through web or via local intranet.

We built an overall management system, consisting of two large sets: one platform for the management of alphanumeric data and documents (mainly not georeferenced images), and one for the management of geographic data (vector and raster). Only open source technologies and programs have been employed for the creation of the system, not only to contain the costs, but also and especially to ensure greater longevity of the digital data, regardless of software licenses and proprietary formats. ${ }^{16}$

\subsection{Alphanumeric data and documents}

Alphanumeric data refers to the tabular data, or even records organized in fields. The database created to manage the activities of MAIKI involves a complex structure able to handle data from different levels of investigation and analysis. The structure specifically developed for this project is able to handle various objects with logical connection between the different levels (fig. 9):

- Entities sites: collects and describes data on a territorial scale of investigation. Archaeological sites can be identified and recorded also on a very large scale, such as the entire territory of the autonomous region of Iraqi Kurdistan, or even the whole territory of Iraq and beyond. Every single site is also container for more detailed entities, as contexts.

- Entities context: usually contained in a site entity. A context represents a set of coherent archaeological investigation and depending on the case may be referred to realities of different sizes. A context can be a single building, a distinct archaeological area within a city or a site, or an isolated excavation trench. Usually a context is a coherent container of stratigraphic units.

- Entities stratigraphic units: collects data of the identified stratigraphic units. These units

15 Regarding holistic approach that new technology can bring to archaeological researches, see Bogdani - Giorgi 2009.

16 Open source applications became a significant part of archaeological research. On this topics relevant workshops are organized and the most important is on an annual basis: Free, Libre and Open Source Software and Open Format in archaeological research process (http://www.archeofoss.org). Of these six meetings only three are published until now: Macchi Jánica - Bagnara (eds.) 2007; Open Source 2009; De Felice - Sibilano (eds.) 2011 
are normally contained in a context entity. Normally a single stratigraphic unit is a container for objects found during the excavation.

- Entities objects: usually collects individual sheets of objects discovered during an archaeological excavation; this entity may also collect data from objects without or from an unknown context, as objects displayed in museum collections, public or private funds, or museums not open to the public (archives). In this case the container of these items are collections and museums.

- Entities collections: are containers of archaeological objects, formed according to different ways (mostly collectors). The collections may be inside a museum or be owned by private subjects.

- Entities museums: collects sheets related to individual museums, which are containers of objects of archaeological interest or entire collections of such objects.

In addition to these hierarchical entities, in the database other transversal entities, which may refer to one or several of the previous, are managed. Among these, the main ones are:

- Entities samples: collects the sheets of samples taken for analysis and their results, and can refer to sites, stratigraphic units or objects.

- Entities documentation: collects the sheets of the various operations of documentation performed on the other entities.

In addition to alphanumeric data, other types of documents (files), mostly not georeferenced images (photographs) and text documents of various types (PDF, MS Office documents, etc.), are managed in the database, always with the possibility to link them with a single element of the entities described above.

For the management of this relational database the employed software is BraDypUS (http://bradypus.net), a software package written using open source languages such as JavaScript and PHP. ${ }^{17}$ The database engine is MySQL; ${ }^{18}$ however it is possible, if necessary, to use the software with other engines server or client (as MariaDB, ${ }^{19}$ PostgreSQL, ${ }^{20}$ SQLite, ${ }^{21}$ etc.). ${ }^{22}$ The servers that host the application and the data are commercial servers located in the EU.

\subsection{Geographic data}

The management of the geographic data requires a greater level of difficulty compared to alphanumeric data, even for the knowledge required to a simple read-only user. For this reason we opted for a different organization of workflow as regards the entry (input) and the output (read) of the data. Servers also require special settings that are generally not available from commercial hosting plans. For this reason a server dedicated to this task, in Bologna, Italy was set up. As in the case of the alphanumeric database, we opted for Open

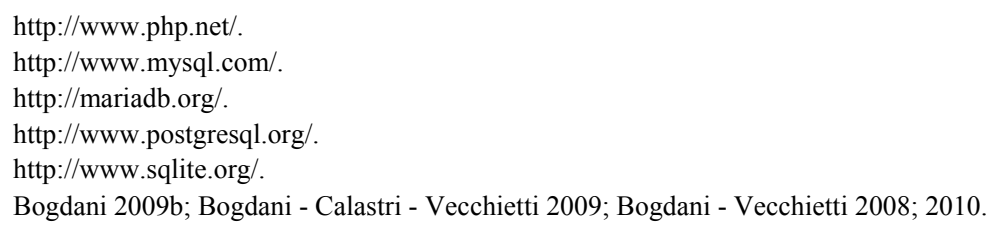


source software; the main motor is constituted by MapServer, ${ }^{23}$ originally developed at the University of Minnesota (fig. 10).

Currently, there are three different degrees of accessing the geographic data, divided as follows:

- Read-only access through a dedicated webGIS interface available online, through a system of access and authentication. Through this interface it is possible to view, navigate and interrogate all the available geographic data, without restriction and without the need to install any specific software, and to work in cloud-computing using a simple web browser.

- Read-only access through WMS and WFS protocols, ${ }^{24}$ which allows connecting to the server through your own GIS software and downloading all data available. This solution is intended for more experienced users, and gives the possibility to create custom maps through queries and appropriated symbology. Furthermore, these two protocols allow performing more advanced analysis of the initial data that is not possible in the first mode.

- Direct read and write access to the main geographical database using a dedicated authentication. This access is restricted to experienced users. Through this access, it is possible not only to view and analyse data, but also edit, delete and add new ones.

As the alphanumeric database, the geographic database is structured to receive data on different geographical scales, beginning with a large spatial scale (vector and raster maps covering almost the entire territory of the Iraqi Kurdistan are currently collected), to an average scale (as may be the area around the city of Erbil, of which different thematical maps are available), to a more detailed scale (as for example the area of the Citadel of Erbil), or even individual buildings and individual contexts up to the position of individual archaeological objects. ${ }^{25}$

The alphanumeric data are also linked to the geographical ones to allow a full integration of all available platforms and the real-time availability of all data.

Julian Bogdani

\section{REFERENCES}

BARCELÓ, J.A. - PALLARÉS, M.

1996 A critique of G.I.S. in archaeology. From visual seduction to spatial analysis: Archeologia e Calcolatori VII (1996), pp. 313-326.

BOGDANI, J.

2009a GIS in archeologia: E. GIORGI (ed.), Groma 2. In profondità senza scavare, Bologna 2009, pp. 421-438.

23 http://mapserver.org/.

24 Web Map Service (WMS: http://www.opengeospatial.org/standards/wms) and Web Feature Service (WFS: http://www.opengeospatial.org/standards/wfs) are largely diffuse standards for the geographic data of the Open Geospatial Consortium (OGC: http://www.opengeospatial.org/).

25 For a more detailed description of the different scales implemented see Bogdani 2012 
2009b Banche dati archeologiche: E. GIORGI (ed.), Groma 2. In profondità senza scavare, Bologna 2009, pp. 439-452.

2012 The Project of an Information System of the Erbil Citadel: C.G. CERETI - R. GIUNTA (eds.), Preservation of Cultural Heritage of the Kurdish Region in Iraq, Bologna 2012 (http://books.bradypus.net/kurdistan, DOI: 10.978.88904294/60).

Bogdani, J. - CALASTRi, C. - VeCCHIETTI, E.

2009 Lo scavo nelle fornaci romane di Albinia (Orbetello, Gr): Materiali per Populonia 8, Pisa 2009, pp. 255-268.

BOGDANI, J. - GIORGI, E.

2010 Tecnologie e metodologie per lo studio del territorio: F. TARLANO (ed.), Il territorio grumentino e la valle dell'Agri nell'antichità. Atti della giornata di studi. Grumento Nova (Potenza), 25 Aprile 2009, Bologna 2010, pp. 145-152.

BOGDANI, J. - VECCHIETTI, E.

2008 Nuove soluzioni in rete per la gestione e la divulgazione del dato archeologico: OCNUS Quaderni della Scuola di Specializzazione in Archeologia 16 (2008), pp. 59-68.

2010 From "text" to "con-text": using the web in the archaeological research: A. CoRALINI (ed.), Vesuviana. Archeologie a confronto, Proceedings of the International Conference (Bologna, 14-16 gennaio 2008), Bologna 2010, pp. 809-818.

CERETI, C.G. - TERRIBILI, G.

2012 The Paikuli Monument: M. AlRam - R. GySELEn (eds.), Sylloge Nummorum Sasanidarum (Band II), Wien 2012, pp. 74-87.

CONYERS, L.B.

$2004 \quad$ Ground-penetrating radar for archaeology, Walnut Creek 2004.

DANIELS, D.J. (ed.)

2007 Ground Penetrating Radar (2 ${ }^{\text {nd }}$ edition) (IET Radar, Sonar, Navigation and Avionics Series 15), Milton Keynes 2007.

De Felice, G. - Sibilano, M.G. (eds.)

2011 Archeofoss. Open source, free software e open format nei processi di ricerca archeologica. Atti del IV workshop (Foggia, 5-6 Maggio 2010), Bari 2011.

DIAL, G. - GRODECKI, J.

2002 RPC replacement camera models: International Archives of Photogrammetry, Remote Sensing and Spatial Information Sciences, Vol. 34, Part XXX, CDROM, 2002.

FORTE, M.

2002 I Sistemi Informativi Geografici in archeologia, Roma 2002.

FRASER, C.S. - RAVANBAKHSH, M.

2009 Georeferencing Accuracyof Geoeye-1 Imagery: Photogrammetric Engineering \& Remote Sensing 75.6 (2009), pp. 634-638

HuMBACH, H. - SKJERVø, P.O.

1978-1983 The Sassanian Inscription of Paikuli, Wiesbaden 1978-1983.

LOCK, G.R. - STANČIČ, Z.

1995 Archaeology and Geographical Information Systems: A European Perspective, London Bristol 1995.

MACCHI JÁNICA, G. - BAGNARA, R. (eds.)

2007 Archeofoss. Open source, free software e open format nei processi di ricerca NOVÁCEK, K. archeologica. Atti del I Workshop (Grosseto, 8 maggio 2006), Firenze 2007.

2009 Research of the Arbil Citadel, Iraqi Kurdistan, First Season: Subartu 3 (2009), pp. $205-$ 246. 
OPEN SOURCE

2009 Open Source in archeologia: ArcheoFOSS: Archeologia e Calcolatori XX, 2009.

Palumbo, G. - Agnew, N. - Myers, D.

2009 The GCI-WMF Iraq Cultural Heritage Conservation Initiative: Building professional Capacity for Cultural Heritage Conservation and Management: Conservation and Management of Archaeological Sites 11.3-4 (2009), pp. 340-350.

YENTER, COL. M.W. ET ALII

2005 Development of the iraqi geospatial reference system: The American Surveyor 2/7 (2005), pp. 12-22. 


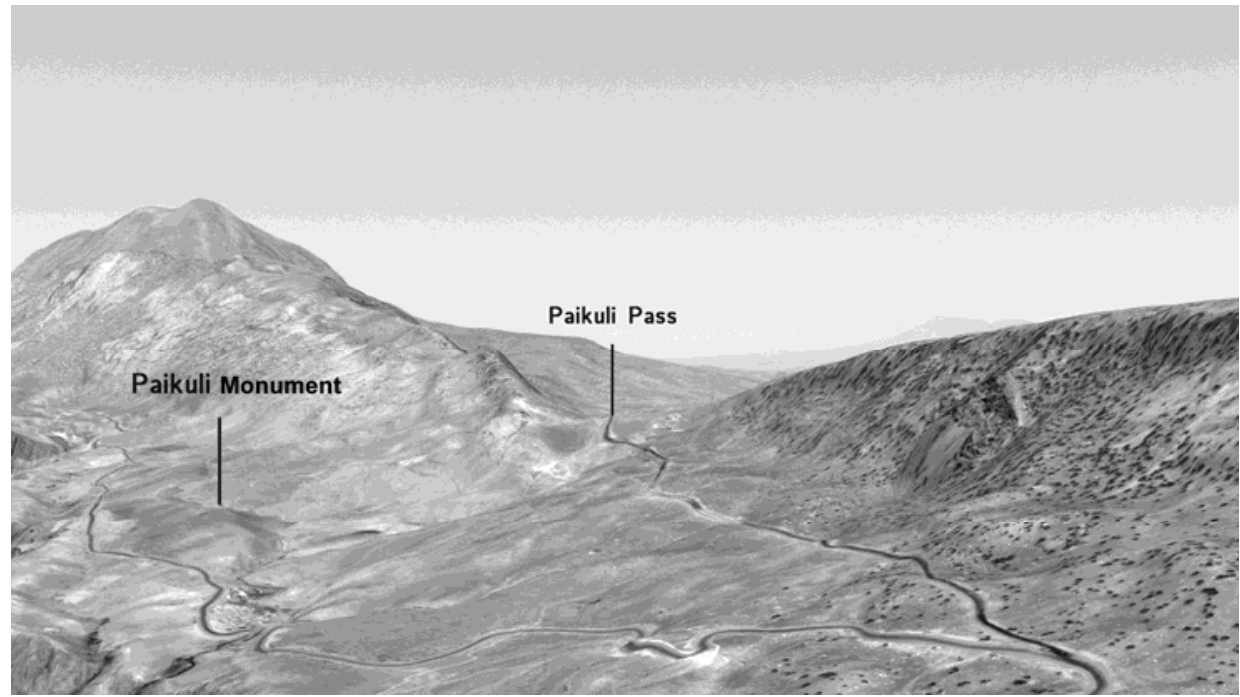

Fig. 1: View of the digital model of the terrain with the orthorectified (through digital stereophotogrammetry) satellite image projected onto it. The positions of the Paikuli monument and mountain pass are respectivley indicated (Image MAIKI, processing Studio 3R).

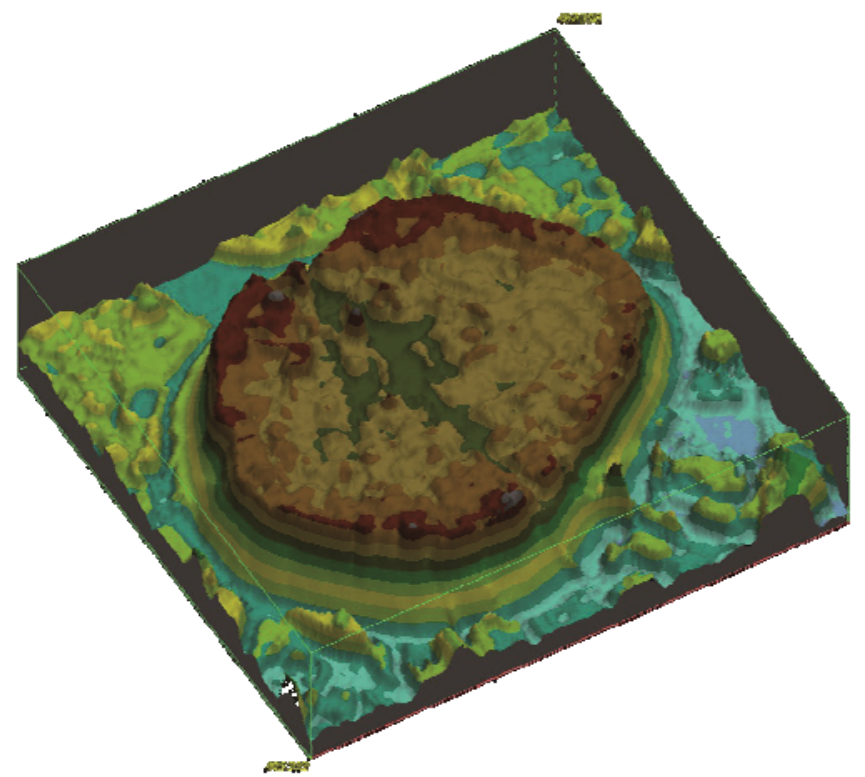

Fig. 2: Erbil, vertically exaggerated solid elevation map of the Citadel (Image MAIKI, processing Studio 3R). 


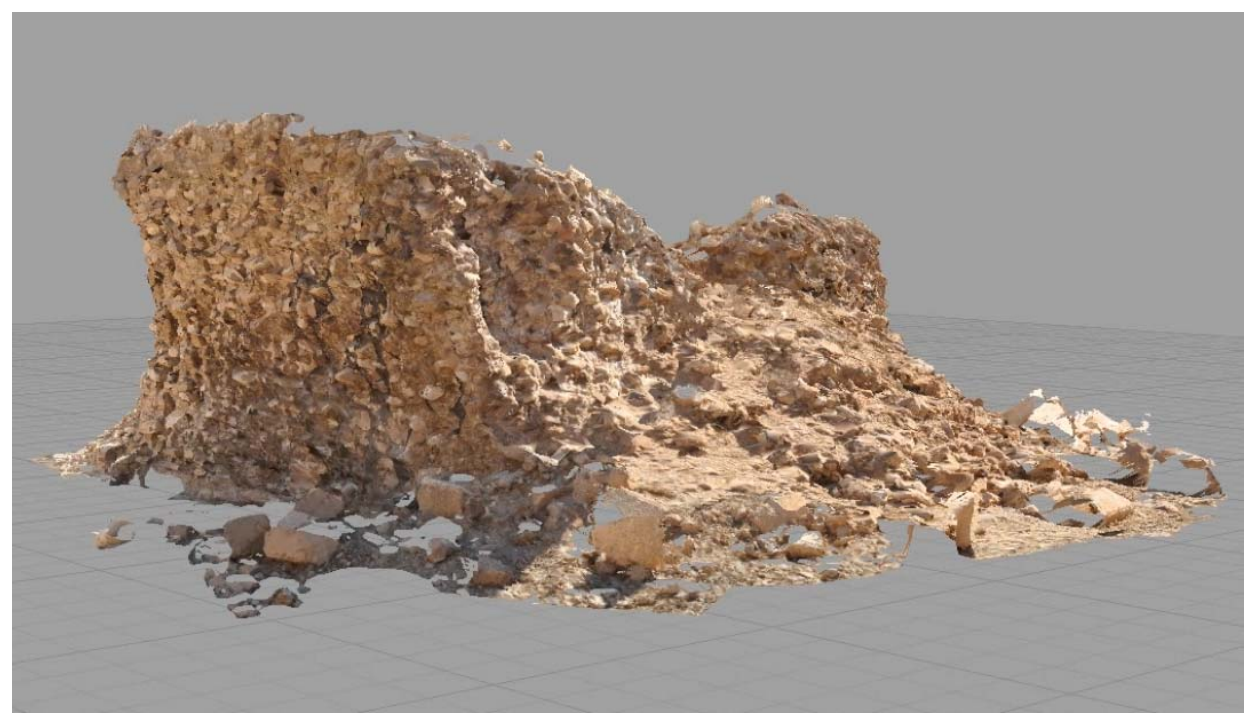

Fig. 3: Paikuli, Point cloud of the monument remains acquired through the Menci Software ZScan photogrammetry system (Image MAIKI, processing Studio 3R).

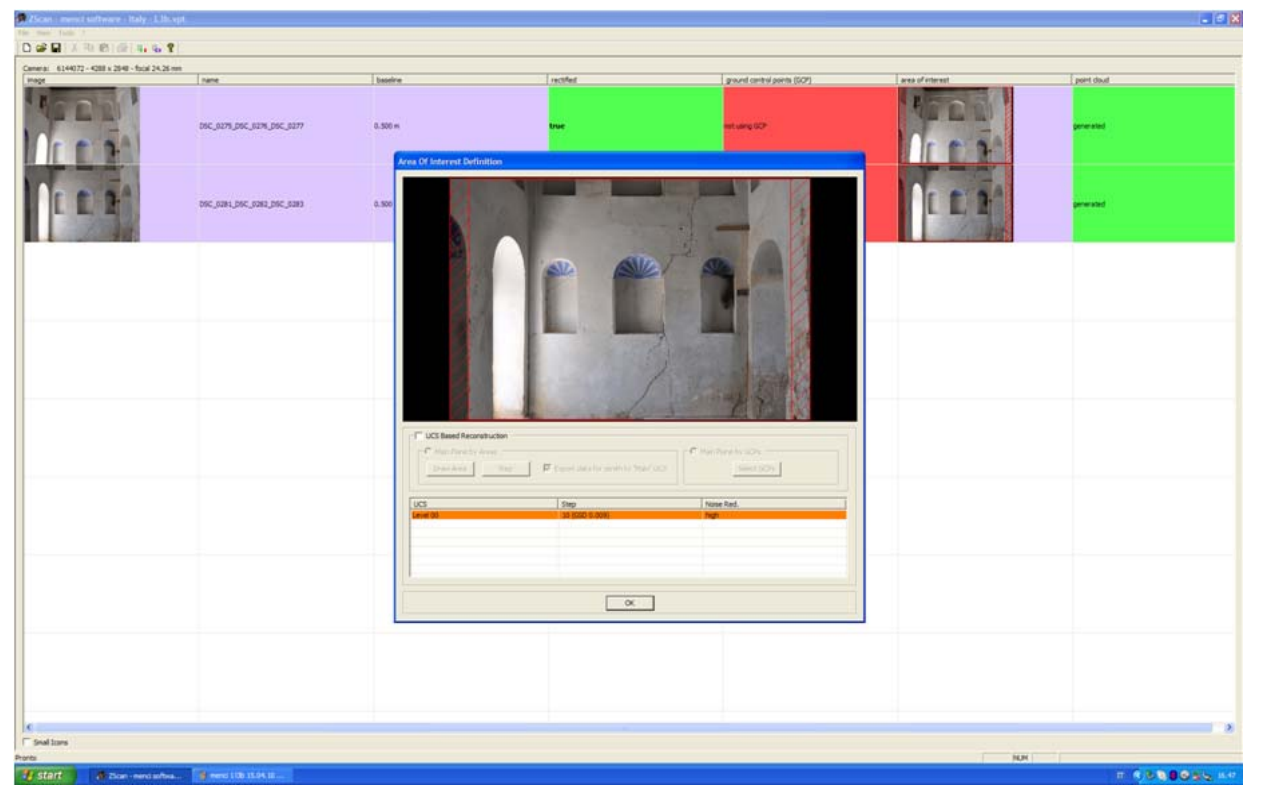

Fig. 4: Erbil Citadel, images processing of the Rashid Agha Diwan Khanah within ZScan (Menci Software; image MAIKI, processing Studio 3R). 


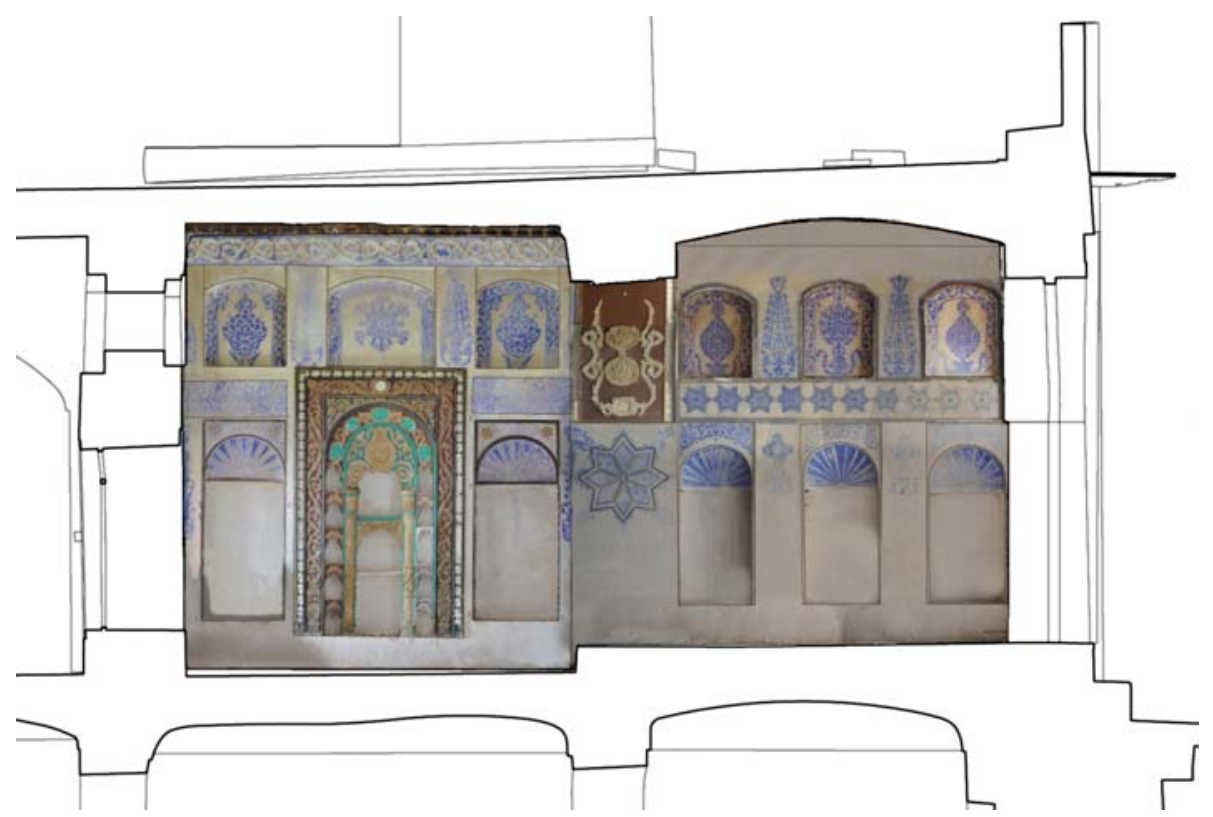

Fig. 5: Erbil Citadel, longitudinal section of the Rashid Agha Diwan Khanah with true orthophotos (Image MAIKI, processing Studio 3R).

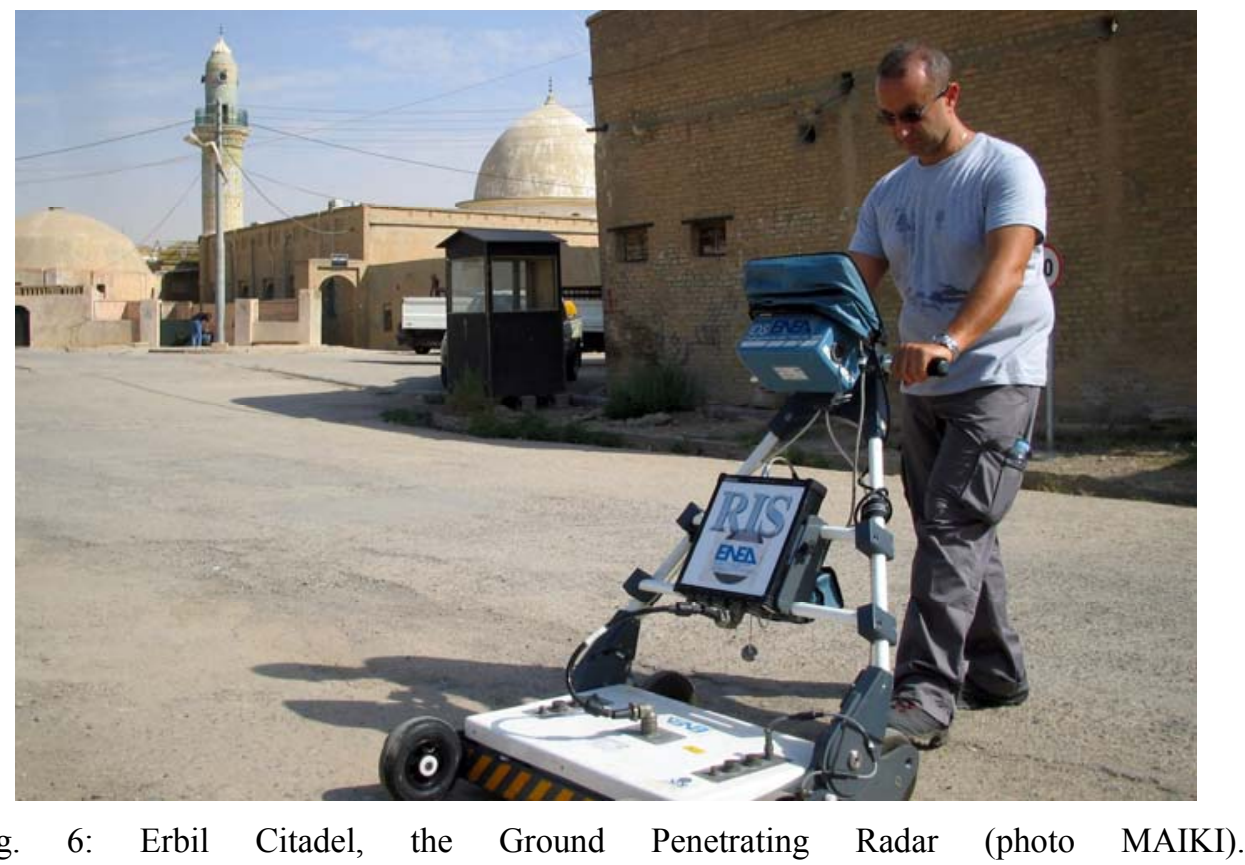

Fig. 6: Erbil Citadel, the Ground Penetrating Radar (photo MAIKI). 


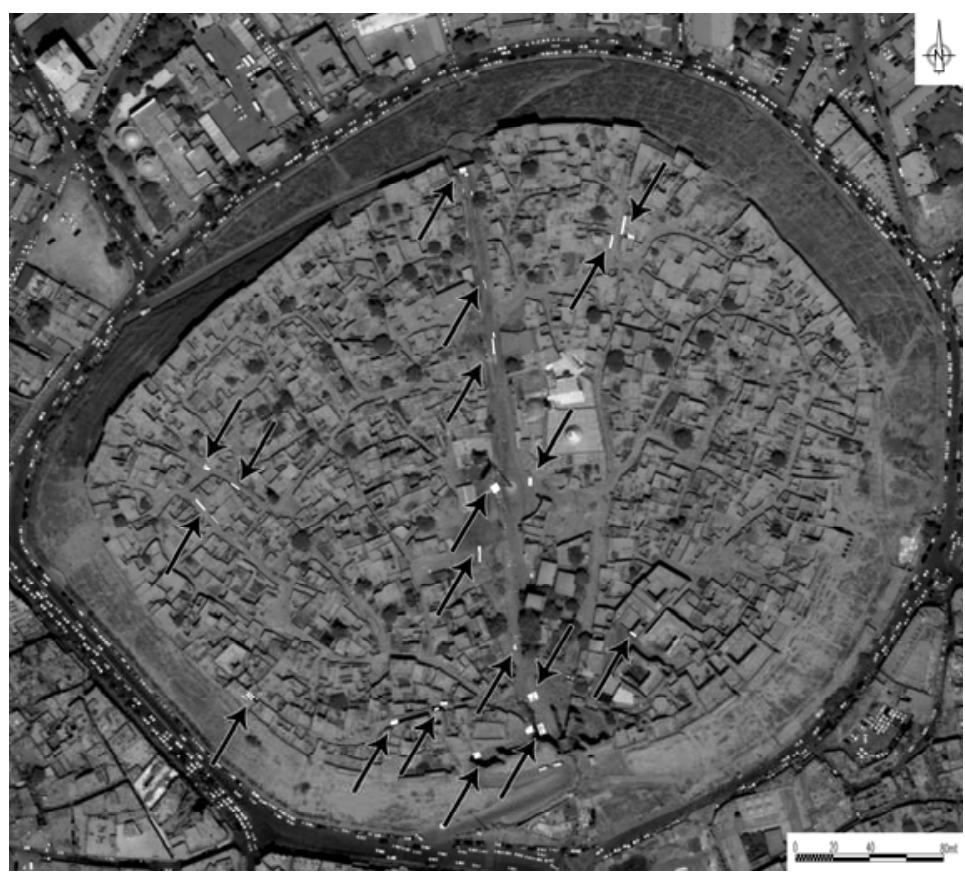

Fig. 7: Erbil Citadel, the GPR survey with founded evidences (Image MAIKI, processing by S.S. Tilia - Studio 3R - L. Colliva).

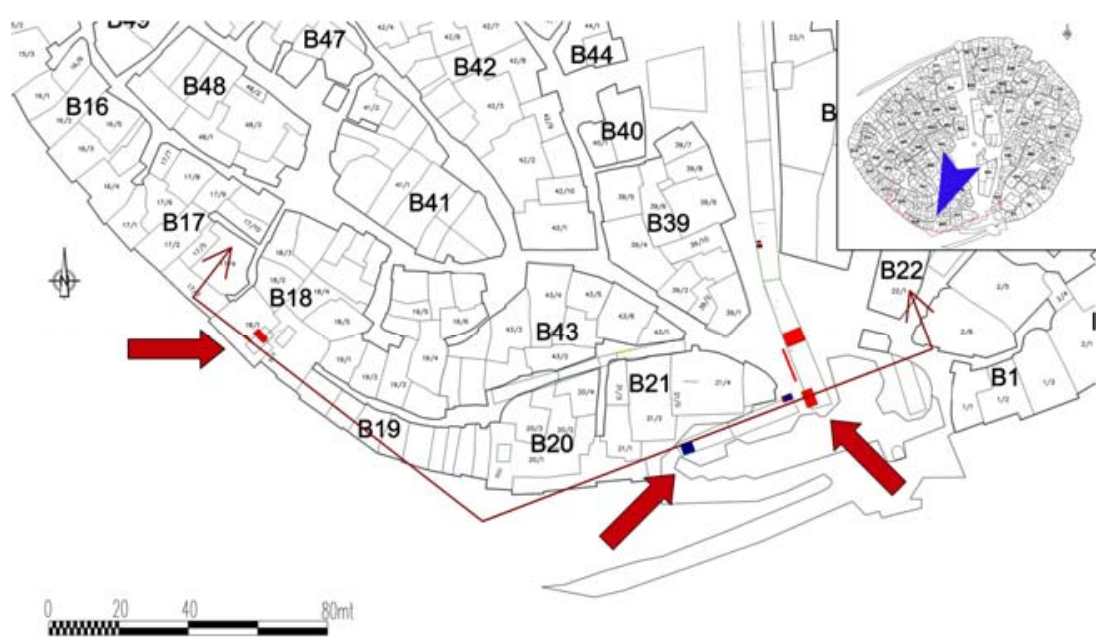

Fig. 8: Erbil Citadel, plan the southern sectors with representation of the identified anomalies (Image MAIKI, processing by S.S. Tilia - Studio 3R - L. Colliva). 


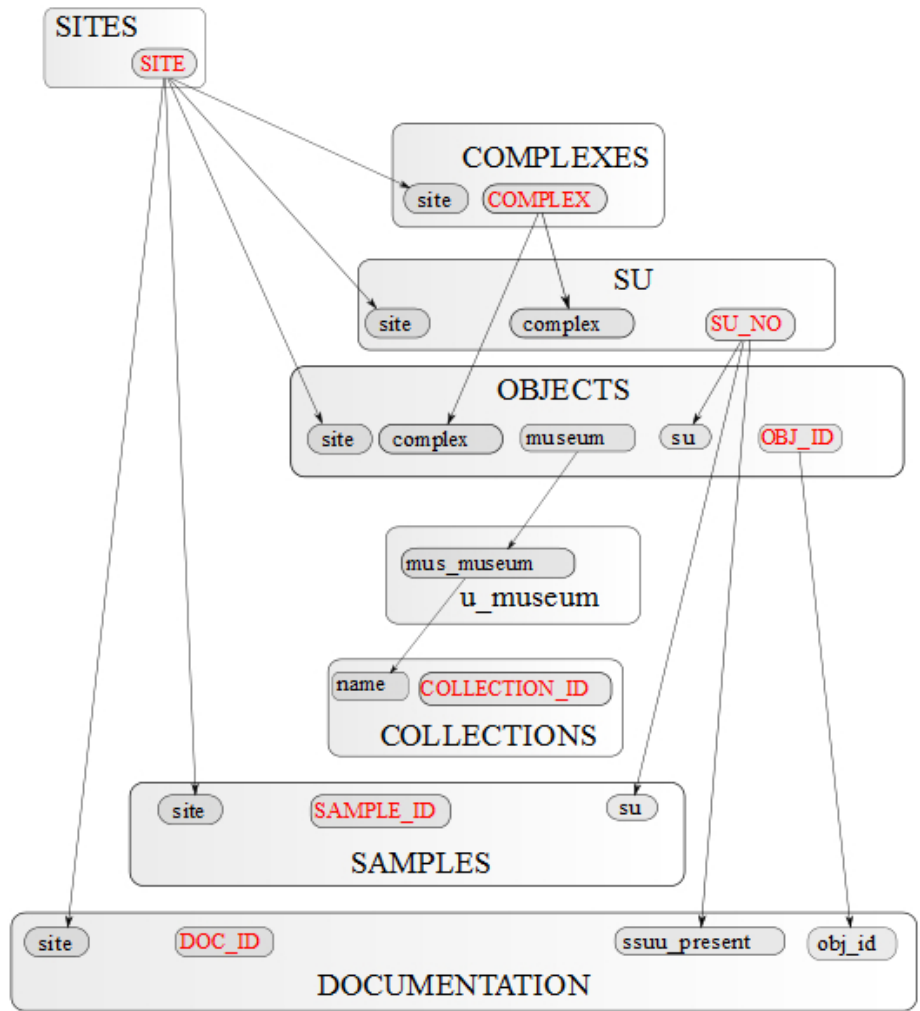

Fig. 9: The Database structure (image MAIKI, processing by J. Bogdani).

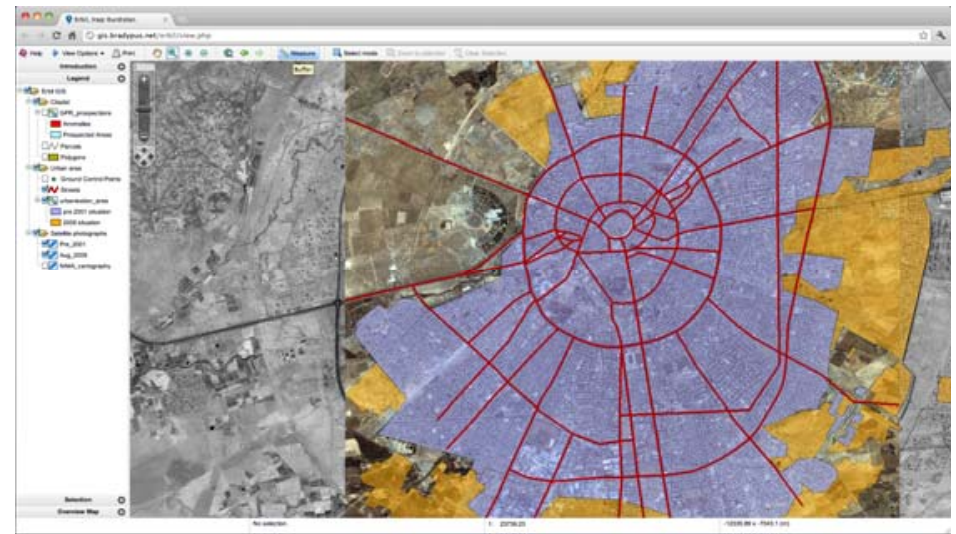

Fig. 10: The Web GIS platform of the Erbil Citadel (image MAIKI, processing by J. Bogdani). 